\title{
The Miracle That Did Happen: Understanding East Asia in Comparative Perspective
}

\author{
Jagdish Bhagwati ${ }^{1}$
}

I am honored by the invitation to give the Keynote speech at this celebratory Conference in honor of Professors Liu and Tsiang. But I am also intimidated: the many distinguished economists assembled here are scholars who know so much more than I do about the subject that I have been asked to address that my participation in the Conference will me an unrequited transfer rather than mere gains from trade.

Perhaps the most productive task I might undertake would be to address the lively debate in recent years over the issue of the East Asian "miracle," in which Taiwan has been a major player. What factors explain this phenomenon? What lessons can the laggard, reforming countries draw from this analysis? Drawing on a historical contrast between India, whose experience I know fairly well from my own research, and East Asia, whose experience I know almost as well from others' research, I plan to argue the following (among many other things):

- that the recent contention (by Paul Krugman, drawing on the Allwyn Young calculations of TFP and growth accounting, ${ }^{2}$ but in fact going back, as I say below, to T.N. Srinivasan in his comments, based on Jong-Il Kim and Larry Lau's earlier TFP calculations instead, on the World Bank study of East Asia) that there was no "miracle" misconstrues what is miraculous about the East Asian growth experience;

1 This is the text of the Keynote speech delivered on May 3, 1996 at Cornell University on the occasion of the Conference on "Government and Market: The Relevance of the Taiwanese Performance to Development Theory and Policy" in honor of Professors Liu and Tsiang. I am thankful for many discussions I have had over the years with Ian Little, Martin Wolf, Don Davis, Vivek Dehejia, Magnus Blomstrom, and T.N. Srinivasan on the issues raised by the East Asian experience. In making the final revisions, I have also profited from the contributions of many of the participants at the Cornell Conference, among them Irma Adelman, Erik Thorbeke, Arnold Harberger, John Cheh, Larry Lau, Gus Ranis, and Henry Wan.

${ }_{2}$ Krugman has advanced this argument in a number of newspapers and magazines, but the chief source is an article in Foreign Affairs, entitled "The Myth of Asia's Miracle," in the November/December 1994 issue. 
- that the miracle consisted in the enormous growth in rates of private investment in these countries, to levels that are almost certainly unparalleled in the experience elsewhere, now or historically;

- that this "fundamental" cannot be explained without assigning a major explanatory role to the region's outward orientation, i.e., to its "export promoting" (EP) as distinct from "import substituting" (IS) trade strategy;

- that, in turn, the growth of export earnings also led to this investment being "implemented" with increasing imports of newer-vintage capital equipment, which embodied significant technical change, whose social contribution exceeded its cost, providing therefore a double whammy (i.e., both high rates of private investment induced by exports and returns from technical change embodied in imports) that raised growth to "miracle" levels over a sustained period;

- that the excess of the social contribution by newer-vintage-capital-goods over their international cost was the larger because of the phenomenally high levels of literacy and education that characterized the East Asian countries, thus reinforcing the second source of contribution to growth noted above;

- that direct foreign investment (DFI), like trade, was equally productive in East Asia, reflecting the high returns to the EP strategy, whereas the IS countries both attracted less sustained inflows of DFI and got less therefrom;

- that "industrial policy," or what Alice Amsden has called "getting prices wrong," has little to do with East Asia's growth and may have even harmed it;

- that this mighty engine of growth, based on outward orientation, must be contrasted with the sluggish locomotive that India's IS-strategy-burdened economy registered, to appreciate the thesis I advance; and

- that the East Asian "model" has already been adopted with dramatic results by the NECs, having traveled west from the NICs, and India in South Asia stands posed to profit from a shift to it as the reforms initiated in 1991 are intensified. 


\section{A Miracle or Not?}

At the outset, permit me to examine the issue whether there was a miracle or not. ${ }^{3}$ To my knowledge, many of us christened the East Asian experience of near and actual double-digit growth rates over nearly a quarter century a miracle; and I have often thought that ours must be a dismal science indeed if anytime a country does remarkably well, we call it a miracle!

Some of the recent critics who contend that the East Asian miracle is a myth seem to take the theological view that a miracle is a phenomenon that cannot be explained. Since growth accounting suggests (what cannot but have been apparent to the scholars of East Asia) that the remarkable growth performance can be explained overwhelmingly by high rates of investment, the miracle ceases to exist: a miracle dissolves the way a paradox is lost as soon as it is explained.

But then there are also those who argue more substantively that the central role played by investment and the absence of significant TFP gains in East Asia means that there was no "miracle" in the different sense that we do not need to invoke or infer some silver bullet or an alchemy such as a wondrous "industrial policy" that we must all imitate or Max Weberite "Asian values" to account for East Asia's special performance.

3 T.N. Srinivasan, "Trade Orientation, Trade Liberalization, and Economic Growth," Yale Economic Growth Center, mimeo, 1996, has recently suggested that the characterization of the Far Eastern performance as a miracle owes to Robert Lucas's lecture on "Creating a Miracle," followed by the World Bank's well known study entitled The East Asian Miracle, both in the early 1990s. However, Srinivasan is not correct. The characterization of the East Asian experience as a miracle, in the sense of an extraordinary performance, predates Lucas for sure. Thus, writing in the late 1980s in my book, Protectionism(MIT Press: Cambridge, Mass, 1988, p.98), I myself had remarked on the Far Eastern experience as a miracle, in the context of arguing that everyone tended to see the miracle as produced by their preferred policy prescriptions: “... how could an economic miracle have occurred if policymakers had not followed our preferred policies? Recalling that public goods have the property that I can enjoy them without depriving you of your pleasure, I have formulated the following law: Economic miracles are a public good; each economist sees in them a vindication of his pet theories." I have no doubt that others have also used the word "miracle" in this sense, both generally and in relation to the East Asian experience, much before Lucas and the World Bank. 
Thus, let me cite T.N. Srinivasan who fully anticipated the later Krugman contention that there was "no miracle." In a forceful commentary on the draft of the World Bank study on the East Asian miracle, he argued as early as July $1993:^{4}$

... the analysis of Jong-Il Kim and Larry Lau suggests that there was no TFP growth in the NIC's. They conclude that "the hypotheses that there has been no technical progress (or increase in efficiency) in the Newly Industrialized countries during the post-war period cannot be rejected. By far the most important source of economic growth ... is capital accumulation accounting for more than 80 percent of their economic growth." (Jong-Il Kim and Lawrence J. Lau, "The Sources of Economic Growth of the Newly Industrialized Countries on the Pacific Rim," Stanford University (processed), December 1992) ... Thus, once does not have to look beyond the neoclassical explanations based on fundamentals ... to understand the East Asian growth. There is no mystery or miracle. And in a subsequent letter to Michael Bruno, a few months later, he went on to argue that, therefore, “...the 'culture' and 'authoritarianism' hypotheses ... ought to be firmly rejected," and that, in any event, other direct arguments could lead one to reject such "exceptionalism" hypotheses.

Equally, Ian Little, in an illuminating pamphlet on the subject, has argued that "exceptionalism" in the shape of "industrial policy" need not be cited either to explain the East Asian miracle, given the enormous and conventional role of investment, while also claiming that, in any event as I say below on the basis of his persuasive arguments, direct analysis of the role of industrial policy suggests that it was neither necessary for East Asia's performance nor harmless to it. ${ }^{5}$

My own view is that, even if the TFP calculations are taken seriously, the East Asian miracle, in the sense of "exceptionalism of outcomes" simply gets to be the miracle of East Asia's phenomenal

\footnotetext{
4 This quote is from a widely-circulated internal memo to the team in charge of the World Bank study, and is dated July 21, 1993. Italics are in the original; boldface has been added.

5 See the pamphlet by Ian Little, "Picking Winners: The East Asian Experience," Social Market Foundation Occasional Paper, London, 1996. I consider the subject of industrial policy in depth later in the Lecture.
} 
increase in investment rates, i.e. it becomes an "exceptionalism of the fundamentals of investment."6 More to the point, since the East Asian investment rate increased in the private sector (whereas similar rises in investment rates occurred in the postwar period in the public sector in the former socialist countries, the latter resulting in blood, sweat and tears but not in growth), the real miracle that requires explanation is that of a phenomenal rise in private investment rates on a sustained basis to high levels, unparalleled as far as I know in any other region or historical period.

\section{Explaining the Miracle: A Synopsis of my Thesis}

In providing this "exceptional-private-investment"-centered explanation, which must be the critical starting point in any explanation of East Asia's miracle or exceptional performance, I will turn today to the region's outward orientation, especially to the adoption of the export-promotion (EP) strategy, and the substantial inducement to invest that the increasingly accessible world market provided, while contrasting it with the adoption of import-substituting (IS) strategy in India which, I shall argue, impaired instead the private inducement to accumulate by limiting it to that provided by the demand generated by the domestic (agricultural) growth rate. ${ }^{7}$

\footnotetext{
${ }^{6}$ In my analysis below, I explain why the inducement to invest was so high as to yield this exceptional investment performance. However, the accommodating increase in domestic savings also had to be remarkable and hence may be treated also as part of the miracle. As far as I can tell, the governments played a role in facilitating this process.

7 This element of my thesis was outlined in a Letter to the Editor, "Private Investment and the East Asian 'Miracle," The Financial Times, January 15, 1996, apropos of Michael Prowse's column which had mentioned the Krugman views in Foreign Affairs. Krugman is wrong in arguing that there is no miracle in East Asia because the high growth can be explained by reference to "fundamentals" such as investment, while forgetting that the miracle lies precisely in these fundamentals being so exceptional: the fundamentals themselves are to be explained. In drawing an analogy between the USSR and East Asia to argue that the latter will grind to a halt the way the former did, Krugman also misses critically important differences between the two areas. The Soviet growth reflected exceptionally high levels of public saving and investment, set within a policy framework where incentives to use resources efficiently and to innovate (both endogenously and through imported technology via trade and investment) were both crippled, so that we would have quite rapidly the observed phenomenon of sagging and then sinking growth rates as illustrated dramatically by Padma Desai's Figure 1.1 (especially for 1955-1979) in her well known analysis, Growth Retardation in the Soviet Economy: Problems and Prospects, Basil Blackwell: Oxford, 1987. By contrast, the East Asian experience is strongly built on exceptionally high private investment and saving, and high levels of absorption of foreign technology, explaining (in the manner outlines in the Lecture below) why the growth process has been sustained over a much longer period and the prospects are equally quite different from those that overtook the Soviet Union.
} 
In turn, I will also argue that the flip side of the EP strategy was the exceptional export earnings which enabled the increased private investments to absorb increased imports of newer-vintage capital equipment whose social marginal product exceeded their international prices, yielding a "surplus" and hence an added boost to the East Asian growth.

Then again, this surplus must have been increased, and the miracle enhanced, by the increment in the social marginal product resulting from the high levels of primary education and literacy, as also the increases in higher education, that could interact meaningfully with the accumulation and imports-ofembodied-technology process that the outward orientation had unleashed and fed.

\section{Dismissing Conventional Exceptionalism Arguments}

But before I develop this argument, let me mention, only to reject, some of the conventional "exceptionalism" arguments that surface from time to time, especially those concerning the region's authoritarian policies, Confucian culture or industrial policy.

The exceptionalism cited to explain away the East Asian performance has taken some strange forms. For instance, it used to be asserted that Hong Kong and Singapore were small "city states" and therefore somehow not subject to economics laws applying to other "normal" nations. Of course, many nations around the world are even smaller on dimensions such as population. Again, coming from India, I recall exceptionalism being applied similarly to explain India's lack of performance: we were an exceptionally "large" country, so what could we expect? Of course, we then had to contend with Brazil and, now, we see China which is even larger (in population) pushing ahead rapidly. But the less outrageous claims of exceptionalism are no more persuasive.

\section{Authoritarianism}

The commonest and superficially plausible assertion, of course, is that East Asia prospered because it had authoritarian rule and that democracy is inimical to growth. It is hard to see authoritarian rule however as either a necessary or a sufficient condition for efficiency or for growth. Indeed, the 
historical record, as also recent postwar experience across nations, underlines the tenuous, even false, nature of such claims.

I suspect that these claims were a result of the Harrod-Domar style of thinking when the postwar period of planning began. ${ }^{8}$ If one treated the marginal capital-output ratio as more or less a technological parameter, as the major development economists of the time such as Paul Rosenstein-Rodan and Jan Tinbergen did, then all policy action was concentrated on raising the average saving rate to increase investment and hence the growth rate. ${ }^{9}$ If public sector saving was considered to be the principal agent for raising the savings ratio, then it was evident that the authoritarian states would be at an advantage over democracies: the former could create the necessary surplus through heroic fiscal efforts that the latter, dependent on popular support, could not. Interestingly, both the Marxist and the Harrod-Domar models produced the same prescription.

But, of course, the reality turned out to be otherwise. For one thing, the East Asian miracle reflects private, not public, savings and investment: its sustained and extraordinary increase itself must be explained by reference to the East Asian policy framework. At the same time, more generally, the variations in growth performance across countries have tended to reflect, not just differences in rates of investment, but also dramatic differences in the marginal capital-output ratio. The latter, in turn, reflects the policy framework and its effects on efficient use of resources. Again, I would argue that the policy framework relevant here includes incentives and democratic processes that both enable and motivate effective participation by the citizenry in the growing economy.

Returning to East Asia, it might still be argued that authoritarian structures permitted these countries to make the right policy choices, uncluttered by democratic pressures. So, if I believe that the EP strategy was at the heart of the East Asian miracle, then the choice of this strategy and its execution

8 I have developed this theme at greater length in my 1994 Rajiv Gandhi Memorial Lecture, "Democracy and Development: New Thinking on an Old Question," published in a slightly abbreviated version in the Journal of Democracy, October 1995. The full text is published in Indian Economic Review, Vol. 30(1), 1995, pp. 1-18. 
with a steady hand must be attributed to the authoritarian structures. But the choice of policy by these non-democratic government could well have been for the IS strategy, as was the case in many other countries in Africa, Latin America, Eastern Europe, and within Asia itself (as in Indonesia).

I have seen no truly compelling explanation of why the East Asian nations, uniquely among the developing nations at the time, chose the EP strategy, on which I have made plain that I plan to lay heavy duty to explain the miracle. Do not count out luck, however. Pertinent examples include the fact the economists we honor today happened to render the right advice to Taiwan; that Saburo Okita, as Head of the Economic Planning Agency, propelled Japan itself towards export-orientation in the late 1950s in teeth of widespread elasticity pessimism; that, by contrast, the influential Indian planner P.C. Mahalanobis in the late $1950 \mathrm{~s},{ }^{10}$ aided by some of India's distinguished economists, propelled the economy towards the harmful IS strategy precisely by taking elasticity pessimism too seriously. ${ }^{11}$

Did East Asia's proximity to Japan, which has followed a similar EP strategy historically, help by diffusing the ideas more readily to the region? But, if so, why did that influence stop right at the four "little tigers"? Besides, the region is proximate also to China which, at least at the time, was considerable alongside India to be a potential superstar in development, so that the IS strategy might have been considered to be easily diffusible to East Asia!

Similar objections can be raised against the hypothesis that these were "island" economies which "naturally" looked backwards, like Japan, and thus embraced the EP strategy. Have we not heard of Jamaica under Manley or of Indonesia under Sukarno and the early Suharto? If all these plausible

\footnotetext{
9 That the marginal capital-output ratio would be constant in the Harrod-Domar model with slack labor force, which would be the case if we also assumed a Lewis surplus-labour economy, is consonant with the point I am making in the text about the capital-output ratio being taken by planners as virtually a technological parameter independent of the policy framework and its effects on efficiency.

10 See, in particular, P.C. Mahalanobis, "The Approach of Operational Research to Planning in India," Sankhya, Vol. 16, 1-2, pp. 3-130.
} 
hypotheses collapse under the weight of scrutiny, it is easy to understand the implausibility of the more farfetched contention that authoritarianism explains the choice by East Asia of the EP strategy; nothing more needs to be said on the subject.

\section{Confucian Values}

The notion that "values" have provided the necessary fuel to ignite the East Asian miracle has appeal to the Weberites and to Prime Minister Lee Kuan Yew of Singapore. It is not that values cannot matter in affecting economic performance: that would be a vulgar and untenable position to take. The problem is rather that the very same Confucian values that were supposed to be a hindrance to development in the Far East are now advanced as having been the engine of growth there: an ex post explanation that seems contrived rather than compelling. Indeed, culture and values seem rarely to provide a strong causal explanation of economic performance and are generally overwhelmed by conventional economic factors in producing or inhibiting economic performance.

Thus, contrast South with North Korea: surely both had identical values at the outset. Or compare East and West Pakistan, both Islamic: the contrasts in their performance before the creation of Bangladesh were striking. Or array the European and Latin American Catholic countries on their growth rates in the postwar period: the differences among them are again quite striking, just as they are among the aggregated Christian countries.

Moreover, an acquaintance with the literature on what the culturalists have said about the critical importance of culture and values to development will make economists generally skeptical of the assertions in regard to the claims in behalf of cultural determinism and its iron grip on development. In

\footnotetext{
${ }^{11}$ I can testify to Saburo Okita's role personally, having gotten to know him in Tokyo in 1962, and I discussed these questions in depth with him, when he and I were Secretaries to the Japanese and the Indian Groups of Wise Men, respectively, to promote Indo-Japanese research collaboration, trade and investment. Okita was Head of the Economic Planning Agency at the time. The Indian economists who worked with models that formally assumed elasticity pessimism to discuss development strategy, drawing policy lessons therefrom, and who therefore may properly be credited with the failures of India's developmental efforts, included K.N. Raj and Amartya Sen. For further discussion of the harmful role of economists in misguiding India's economic policy, see my Radhakrishnan Lectures at Oxford, India in Transition, Clarendon (Oxford University) Press, Oxford, 1993.
} 
particular, many of these claims turn out to be specious, the alleged differences being themselves a product of differences in economic opportunity and circumstance. Thus, for example, in the context of Japan, James Fallows had argued, in a series of influential articles on Japan where he sought "containment" of Japan and (citing Rudi Dornbusch's earlier proposal in the New York Times to give Japan import targets and to whip it with across-the-board tariffs in case of noncompliance) asked for punitive tariffs on Japan of 20-25 percent, ${ }^{12}$ that one cannot expect Japan to open markets through rules and must impose import targets (i.e. VIEs) on them because the Japanese are not into abstract thinking and prefer to deal with concrete quantities (such as VERs in trade) rather than rules (as at the GATT). Of course, as anyone familiar with Japanese trade history knows, VERs were imposed on Japan, starting in the 1930s, because we did not wish them to trade by rules; their exports were growing too fast for our industries' comfort. This Japanese learned to trade by quantities, rather than by rules, because we would not let them export by rules: it was our demands, not their culture, that was the culprit. ${ }^{13}$

Let me also cite my favorite quote on misguided cultural inferences. In 1915, an Australian productivity expert invited to Japan had the following to say to the government about the Japanese workforce:

My impression as to your cheap labor was soon disillusioned when I saw your people at work. No doubt they are lowly paid, but the return is equally so; to see your men at work made me feel that you are a very satisfied easy-going race who reckon time is no object. When I spoke to some managers they informed me that it was impossible to change the habits of national heritage.

Such examples could be multiplied readily from our own time, of course.

12 In a New York Times op-ed article on February 22, 1996, provocatively titled by them "What Buchanan owes Clinton," I noted that Pat Buchanan had picked up his specific trade policy proposals from mainstream policy wonks and others, many uncomfortably close to the current administration. Thus, for instance, Buchanan has asked for a $10 \%$ across-the-board tariff against Japan, a moderate proposal compared to the 20-25\% tariff argued for by Fallows, and in a tone that is less alarmist and accusatory than that adopted by the leading Japan-baiting economists. 


\section{Industrial Policy}

It is harder to dismiss, however, the exceptionalism attributed by some, especially Robert Wade and Alice Amsden, ${ }^{14}$ to the industrial-policy interventions of East Asia. I do think that there is a beneficial role to be assigned to governmental interventions in the East Asian miracle, in the early takeoff period of the 1950s when these economies (as also India) were being kicked up into a bastardized, Rosenstein-Rodan-Vishny-Shleifer superior equilibrium, as I will argue below. However, the notion that interventions, especially in the nature of industrial policy, played a systematically beneficial role for decades thereafter (and furthermore that outward orientation played a passive, not an active, role in explaining export and economic performance) is not persuasive to me, though it has gained my colleague Dani Rodrik as a convert or, perhaps I should say, as a victim.

With Alice Amsden at this conference, I realize that I am bearding the lion in her own den, if I may mix metaphors genderwise. But let me make two critical observations. First, even if industrial policy was important, the metaphor that it amounts to "getting prices wrong" is inappropriate. Two propositions are essential to making good policy: one must always get one's prices right; and, in the presence of market failures, the right prices which economists call shadow prices will generally differ from market prices. To combine those propositions into the proposition that one must generally get prices wrong (because presumably there are market failures) is to add two positives to get a negative: a generally invalid procedure despite the philosopher Sidney Morgenbesser's classic response in rich Yiddish to Noam Chomsky (when Chomsky argued that two positives did not make a negative in any language): Ya, Ya?

But linguistics aside, I have a more serious reservation. Of course, contrary to the claims made by the revisionists who embrace industrial policy, the fact that the East Asian superperformers, with the exception of Hong Kong, had interventions, including in the credit and trade markets, was well known to

13 I have discussed this issue in my Harry Johnson Lecture, published as The World Trading System at Risk, Princeton University Press, 1991. 
many of us who wound up assigning little role to this bit of information in the well known OECD studies directed by Ian Little, Maurice Scott, and Tibor Scitovsky in the late 1960s and in the NBER studies in the early 1970s directed by me and Anne Krueger. We may have been wrong, but we were certainly not ignorant.

The real issue is therefore whether these interventions can be regarded as having had a substantial, and a positive, effect. Here, the Bhagwati-Krueger NBER project finding for South Korea was that, when quantified into ad valorem equivalents - a procedure I admitted was not very satisfactory from an analytical viewpoint - the diverse quantity interventions and subventions did not significantly alter the pattern of incentives that world market prices would have provided. ${ }^{15}$

The World Bank analysis of the East Asian miracle ${ }^{16}$ has subsequently argued that, contrasted with expectations of sectoral patterns predicted from endowments (as estimated in ways that can be disputed), there is no conclusive evidence that the sectoral developments were different from the predictions and, for South Korea, the evidence is conclusively so since the sectors growing most during 1968-1988 were the labor-intensive ones whereas the governmental interventions were, if anything, in favor of other sectors. The World Bank study thus concluded: "the quantitative importance of government intervention to alter the structure of production is not confirmed at the sectoral level."17

This conclusion, of course, is correct as a "central tendency" and does not mean that specific sectors were not influenced by activist industrial policy. Thus, Little (page 19) has argued that "common sense tells one that the timing, scale and pattern of investment in heavy industry - especially cars, shipbuilding, and petrochemicals - was markedly different from what would have occurred under laissez faire (or under some non-selective industrial promotion)." It is pertinent therefore that the sectors favored

14 Cf. Alice Amsden, Asia's Next Giant: South Korea and Late Industrialization, New York, Oxford University Press, 1989; and Robert Wade, Governing the Market: Economic Theory and the Role of the Government in East Asian Industrialization, Princeton University Press, Princeton, 1990.

15 This finding was based on the South Korea study in the NBER project by Charles Frank, Kwang Suk Kim and Larry Westphal (South Korea, Columbia University Press: New York, 1975) and discussed in my overall synthesis volume, The Anatomy and Consequences of Exchange Control Regimes, NBER, Ballinger \& Co.: Cambridge, Massachusetts, 1978.

${ }_{16}$ The East Asian Miracle, Economic Growth, and Public Policy, Oxford University Press, 1993.

${ }^{17}$ Ibid., page 333, quoted in Little, op. cit., page 19. 
by the industrial-policy proponents in South Korea are precisely the ones with lagging productivity performance. Little quotes the recent Dollar and Sokoloff finding that "TFP growth in the most capitalintensive sectors (many the object of industrial policy promotion) was less than half that in the most labor-intensive sectors. Electrical goods; rubber, leather, and plastic products; furniture; and clothing and footwear all show above average TFP growth." 18

In addition, I find particularly compelling Little's qualitative arguments, based on his intimate knowledge of Taiwan and South Korea, which militate against the thesis that industrial policy was both comprehensive and, where applied, also beneficial. Thus, let me quote just a few of the many telling examples he gives for South Korea, right after he has measured the social returns from Korean heavy industry and found them to be "bad news for heavy industry fundamentalists, and those who stress the importance and value of the government's industrial policies.": ${ }^{19}$

In 1975 I led a small team which investigated on behalf of the Asian Development Bank the performance of 28 randomly selected medium-size firms which had received loans from the Medium Industry Bank. Since the bank was government-owned it might be thought that our sample firms were selectively promoted. This was not so. The government's guidelines to the bank gave priorities which covered every kind of industry except non-traded luxury consumer goods. (The bank agreed that confectionery was probably the only exclusion.) This, incidentally, suggests that the extent to which the government directed finance (because it owned the banking system) is sometimes exaggerated by the revisionists.

The main steel company, POSCO (the only important state enterprise in the industries mentioned), has had low financial returns throughout its 20 year life despite heavy subsidization of its non-traded inputs, including the real interest rate which has been negative throughout most of its life. It has also received protection (the import tariff

18 Little, op. cit., page 19, citing David Dollar and Kenneth Sokoloff "Patterns of Productivity Growth in South Korean Manufacturing Industries, 1963-1979," Journal of Development Economics, Vol. 33, pp. 309-327. 
on steel was $25 \%$ until recently). Despite this, pre-tax income as a percentage of assets averaged only $4.6 \%$ from 1973-87 ... POSCO may even had negative social returns.

I find myself therefore in sympathy with Little's conclusion that industrial policy in South Korea cannot be regarded as successful. His retort to Wade seems quite persuasive to me: ${ }^{20}$

"[The revisionists] do not question the proposition that industrial policy was successful [because government leadership fixed some market failure or another]. To quote Wade (1990, pp. 305-6): “...the balance of presumption must be that government industrial policies, including sectoral ones, helped more than hindered. To argue otherwise is to suppose that that economic performance would have been still more exceptional with less intervention which is simply less plausible than the converse.' Since the less interventionist Hong Kong, Singapore, and Taiwan grew faster than Korea, it is unclear why Wade thinks it simply less plausible that less intervention would have been better, given also the widespread failure of government industrial policies elsewhere. I find it simply more plausible that Korea grew fast despite its industrial policies, than because of them."

\section{Why the Miracle Happened}

So, having assessed and found unpersuasive the three most popular views about the miracle's source, let me turn to my own thesis, which I sketched earlier in the barest outline.

I must confess that it was suggested to me while contemplating the contrasts between the Indian and the East Asian experience. I hope to persuade you that this sort of "comparative economics" is revealing in a way which many-country regressions (regressing, say, growth rates in 100-plus countries on proxies for natural resources, openness of the economy, et al., on the RHS of the estimated equation)

19 Little, op. cit., page 22; the following quotes are from pp. 22-24.

20 Little, op. cit., page 12. 
are not. I find it difficult to see what I can reliably learn by putting Poland, Outer Mongolia, Venezuela, India, and Singapore, among many others, on one regression line. While running such regressions can be suggestive of hypotheses one has not thought of, I am afraid that their ability to persuade is crippled by the twin facts that the cross-country data are generally commensurable and comparable whereas the context within which these data must be understood and assessed is vastly different across countries. The inevitable destiny of such regressions across 100-plus countries is thus to be dismissed by serious scholars as irrelevant when they do not conform to one's intuition and theories, and to be cites as corroboration when they do.

I believe that the stylized "story" of the East Asian miracle, and its absence in India, can be told in two Phases. I emphasize the fact that my account is a sketch of what I think to be the essential elements of the analysis; it therefore builds on stylized facts as I understand them, whereas a complete account would have to bring in many details that I cannot possibly encompass or even claim to know.

\section{Phase 1}

The first Phase of enhanced India, and East Asian, ${ }^{21}$ growth during the 1950s must principally be explained, I believe, by reference to the Rosenstein-Rodan argument that has now been formalized by Vishny and Shleifer in their fine article in the Journal of Political Economy as a case of multiple equilibria. In his classic 1943 Economic Journal article, which is arguably the most beautiful piece of creative writing on development, Rosenstein-Rodan was basically arguing that, for developing countries stuck in a Nash equilibrium with low levels of investment, there existed a superior cooperative equilibrium with higher levels of investment and growth.

\footnotetext{
${ }^{21}$ Phase 1 may be set in part of East Asia as dating into the early 1960s; but this is a matter of judgment and detail of little consequence to my argument. Besides, Phase 1 may even be considered absent in Hong Kong, which had the unique advantage of an abundant entrepreneurial class and an entrepot economy that was already outward oriented from the outset. I might add that the notion that East Asia's investment growth in Phase 1 did not depend on outward orientation or EP strategy in trade will come as no surprise to any scholar in the field, though it is sometimes presented as if it was a modern discovery that somehow discredits those who talk of the critical role of EP strategy (which applies, of course, to Phase 2).
} 
The Indian planners, in formulating the First Five Year Plan (1951-56), basically were exploiting this insight. This was an indicative Plan, without the straitjacket of controls and targeted allocations that would presumably reflect the contours of the superior equilibrium. In fact, it is absurd to imagine that anyone, either in India or East Asia, could have worked out such a Rosenstein-Rodan-Vishny-Shleifer equilibrium even if there had been complete information to do so! What did happen instead was that the large component of public spending on infrastructure which was built into these indicative programs made the government's commitment to kicking the system up into some bastardized version of the Rosenstein-Rodan-Vishny-Shleifer equilibrium quite credible to the private sector, triggering the selffulfilling private sector investment response that lifted the economy into higher investment and growth rates. $^{22}$

Phase 2

But, at the end of the 1950s, the policies of the two regions diverged in ways that would set them dramatically apart in their economic performance. The critical difference was that India turned to the IS strategy, East Asia to the EP strategy.

1. Inducement to Invest: India thus handicapped the private inducement to invest, while East Asia wound up enhancing it. India turned it inwards, starting with the balance of payments crisis in 195657 which precipitated the imposition of exchange controls which then became endemic to the regime, reflecting the currency overvaluation that implies the effective pursuit of an IS strategy. Again, the explicit pursuit of an IS strategy was also desired, reflecting the economic logic of elasticity pessimism that characterized the thinking of India's planners.

The result was that the inducement to invest in the economy was constrained by the growth of demand from the agricultural sector, reflecting in turn the growth of that sector. But agriculture has

22 Dani Rodrik seems to share broadly this view of how private investment rose but seems to err in two ways. He seems to suggest, presumably in sympathy with the Amsden-Wade thinking, that the bureaucrats could figure out the sectoral contours of the superior equilibrium, a presumption that I find ludicrous, especially having seen the best 
grown almost nowhere by more than 4 percent per annum over a sustained period of over a decade, so that increment at the margin in India's private investment rate was badly constrained by the fact that it was cut off from the elastic world markets and forced to depend on inevitably sluggish domestic agricultural expansion. Thus, it became customary for Indian economists to talk about "balanced growth" and about the problem of raising the investment rate which, by the mid-1980s, was still in the range of 1920 percent.

By contrast, the East Asian private investment rate began its takeoff to phenomenal levels because East Asia turned to the EP strategy. The elimination of the "bias against exports," and indeed a net (if mild) excess of the effective rate for exports over the effective exchange rate for imports (signifying the relative profitability of the foreign over the home market), ensured that the world markets were profitable to aim for, assuring in turn that the inducement to invest was no longer constrained by the growth of domestic market as in the IS strategy. Private domestic savings were either raised to match the increased private investment by policy deliberately encouraging them or by the sheer prospect of higher returns.

This argumentation is not easy to defend once you face up to what my student Don Davis, now at Harvard, has called the "tyranny of Stolper-Samuelson": for, when this theorem holds, wages and rentals on capital are inversely related. ${ }^{23}$ When exports are labor-intensive, the EP strategy may be expected to raise the wage of labor but depress the return to capital, thus depressing, not raising, the inducement to invest. Clearly, therefore, the force of Stolper-Samuelson must be broken: as indeed it can be by relaxing one or more of the assumptions underlying that theorem.

Thus, Davis suggests that the forces of comparative advantage may be argued to have been sufficiently strong as to make East Asia specialize in the production of the labor-intensive goods. This "decouples factor returns from the factor price frontier for the capital intensive good, leaving wages and

bureaucrats in India confess to their inability to choose industrial favorites on any rational grounds. Moreover, he extends the argument well beyond the 1950s whereas, as I argue later in the text, this makes little sense.

${ }^{23}$ I am drawing here on the preliminary draft of Don Davis's paper, “Miracles of Accumulation': Models of Trade and Growth in East Asia,” Department of Economics, Harvard University, January 1996. 
rentals dependent only on productivity in the labor intensive good and the price of that good. In moving from autarky to free trade, both factor prices can rise, inducing an accumulation 'miracle'." Another way out would be to assume productivity differences across countries, as in Ricardian theory. In this case, "if we assume that the relative productivity gap of East Asia relative to the rest of the world is largest in the capital intensive sectors, and that trade serves to close this gap, then it is again possible for both wages and rentals to rise.",24

While therefore it is possible to formalize the argument I have made that the EP strategy increased the inducement to invest, I must also address Dani Rodrik's recent objection that exports were relatively small part of the economy at the outset so that EP strategy could not have resulted in any significant impact, and therefore the source of the investment must be found in governmental subventions and interventions whereas the growth of trade is simply a passive result of the growth induced by these other factors. But this argument is totally unpersuasive because East Asia would have run into precisely the problem of demand constraint that India was afflicted with if an IS strategy had been followed, with the efficacy of these other policies in generating investment seriously impaired. Moreover, the ultra-EP strategy, with its mild bias in favor of the export market and the policy-backed ethos of getting into world markets, meant that the export incentives must have played a major role in influencing investment decisions, not just in the exporting countries, but also in the much larger range of nontraded but tradeable industries. ${ }^{25}$ In any event, the growth of exports from East Asia was so phenomenal that the share of initial exports in GNP quickly rose to levels that would lay Rodrik's objection to rest, even if it were conceptually correct.

\footnotetext{
${ }^{24}$ Don Davis, ibid., page 2. Davis proceeds to formalize these ideas in a dynamic framework, more appropriate to the accumulation problem at hand.

${ }^{25}$ Rodrik also seems to think it pertinent that the export incentive, in the shape of the real exchange rate, did not continue improving. However, it is not necessary for it to be improving continuously for the export incentives to operate. Thus, an excess of the effective exchange rate for exportables over that for importables (as distinct from continuous increase in this difference) will suffice to provide a continuing incentive for the export over the home markets. Cf. Dani Rodrik, "Getting Interventions Right: How South Korea and Taiwan Grew Rich," Economic Policy, April 1995. Martin Wolf has also critiques Rodrik's anti-EP-strategy argumentation, as also the Krugman
} 
2. The Imports of Newer-Vintage Equipment: The flip side of the process was, of course, the generation of substantial export earnings that enabled the growing investment to be implemented by imports of equipment embodying new technical change.

Now if the Social Marginal Product (SMP) of this equipment exceeded the cost of its importation, there would be a "surplus" that would accrue as an income gain to East Asia and would also, as I argue below, boost the growth rate. For this argument to hold, however, the international cost of the newervintage equipment must not reflect fully its SMP for East Asia. In a competitive international market for equipment, therefore, I must assume that East Asia was a small player whose higher SMP did not pull up the world price to reflect the higher SMP, i.e. that East Asia could, even without "piracy" and "theft" of intellectual property (which was widespread in the region until the new WTO regime), get embodied technology at bargain prices. This seems a reasonable assumption to make, especially when one sees that the world prices of the last-but-one vintage equipment fall drastically due to rapid obsolescence in the presence of quick product innovation: just think of your PCs. (To understand fully the foregoing point, note that an economy in 1970 such as Soviet Russia's which was confined to using its own 1930s-vintage technology in equipment would not lose to East Asia which could use a heuristically 20 times more productive 1960s technology if East Asia had to pay a 20 times greater price for it. The surplus arises because East Asia pays, say, only a 5 times greater price in world markets for equipment that is 20 times more productive in East Asia.)

This argument is illustrated in Figure 1 in a simple diagram, with the SMP curve for increasing imports of the vintage capital equipment for East Asia put against the international cost of importing it, the striped area then representing the surplus that accrues to East Asia.

argumentation, in two excellent recent Columns in the Financial Times, "The Tyranny of Numbers" and "A Lesson for the Chinese." 


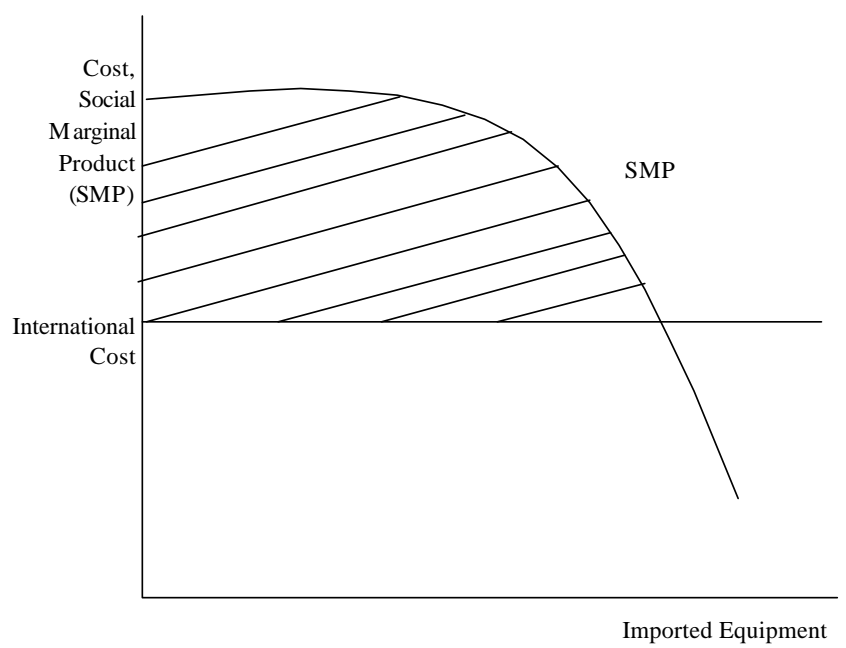

Figure 1

But there may also be another reservation about this argument's effect on the growth rate, as distinct from its effect on income. It is fair to say that, thanks to the focus on the steady state in Solowtype models, it has now become fashionable to assert that the gains from trade, like any allocative efficiency gains, amount to one-time gains, not affecting the growth rate. This is however a wrongheaded general assertion. Thus, consider the simple Harrod-Domar corn-producing growth model with labor a slack variable. If allocative efficiency regarding land use (say, from one inefficient farm to another efficient farm) leads to a greater return to the total amount of ("invested") corn being put into the ground, the marginal capital-output ratio will fall, ceteris paribus, and lead to a permanently higher growth rate. Similarly, it takes no sweat for a first-rate theorist to construct models where trade in capital goods leads to higher growth rates, without building in externalities, etc., and relying exclusively on the fact that they can be imported more cheaply than constructed under autarky. 
T.N. Srinivasan has extended Mahalanobis-type putty-clay model to include trade and demonstrated precisely this. ${ }^{26}$ Thus, he assumes (in place of just one capital and one consumer good in autarkic version) that there are two of each class of goods, with the marginal product of capital constant in each sector as in the Harrod-Domar model. The social utility function and the function that transforms the output of the two investment goods into aggregate investment are Cobb-Douglas. There is no intersectoral (i.e. between the consumer goods and the capital goods sectors), as against intrasectoral (i.e. between the two goods in each sector), mobility of capital: this is the clay assumption.

Assuming that all four goods are produced under autarky, that free trade is undertaken at fixed terms of trade, and that the share of investment going to augmenting capacity in each of the two sectors is fixed endogenously, Srinivasan then demonstrates plausibly that free trade in consumer goods (but with autarky continuing in investment goods) will raise welfare relative to autarky but not affect the growth rate of income or utility. On the other hand, freeing trade in investment goods will have a positive effect on transitional as well as long-run (steady-state) growth effect, and also a beneficial welfare effect relative to autarky. The vulgar belief that trade gains cannot affect the growth rate is thus easily disposed of.

However, how does one reconcile the "surplus" argument with the findings that TFP growth has been a negligible factor in East Asia? So, is my story plausible but not borne out by the facts, as is often the case with our most interesting theories? I think not.

Thus, consider precisely the case where the imported equipment is 20 times more productive in Period 2 than in Period 1, but its price is only 5 times as high. If the valuation of this equipment is at domestic (producer) opportunity cost, as it should be, then it will indeed be priced 20 times higher than the older-vintage equipment of Period 1, so the measure of capital contribution at the level of the industry

${ }^{26}$ See his 'Comment on 'Two Strategies for Economic Development: Using Ideas and Producing Ideas,' by Roemer," Proceedings of the World Bank Annual Conference on Development Economics 1992, World Bank, Washington DC, 1993. Srinivasan also makes the valid point that the Mahalanobis-Feldman putty-clay models are among the earlier examples of "endogenous" growth theory since the growth rate is determined by the discretionary policy choice of the share of investment goods being allocated to the capital goods sector. The neglect of the considerable literature on such models by the originators of the current endogenous growth theorists is to be attributed to the fact that these theorists have come to their models from the Solow model and have no acquaintance with the growth models that came up in the context of developmental problems in the 1960s. Of course, most of us are rediscovering great ideas all the time! 
will rise commensurately and I presume that the estimated TFP growth in the industry will be zero: in that case, my thesis about the surplus is totally compatible with measured TFP emerging as negligible. But, of course, if the equipment is priced at its international cost, then I presume that TFP growth will pick up three-fourths of the gain that accrues from the "surplus" of SMP over the international cost. My guess then is that, in East Asia, the former was the case. This might have been, not because the accountants were smart and valued Period 2 equipment at domestic opportunity cost, but because I guess that much of the imported equipment may have gone through importing trading firms which collected the three-fourths premium rather than the producing firms.

\section{Literacy and Education}

The role of literacy and education comes in precisely at the stage of the second step in my story above. For, the productivity or SMP of the imported equipment would be greater with a workforce that was literate and would be further enhanced if many had even secondary education. Thus, as shown in Figure 2, the SMP curve would shift to the right with literacy and education, leading to greater surplus for any given international cost of newer-vintage equipment.

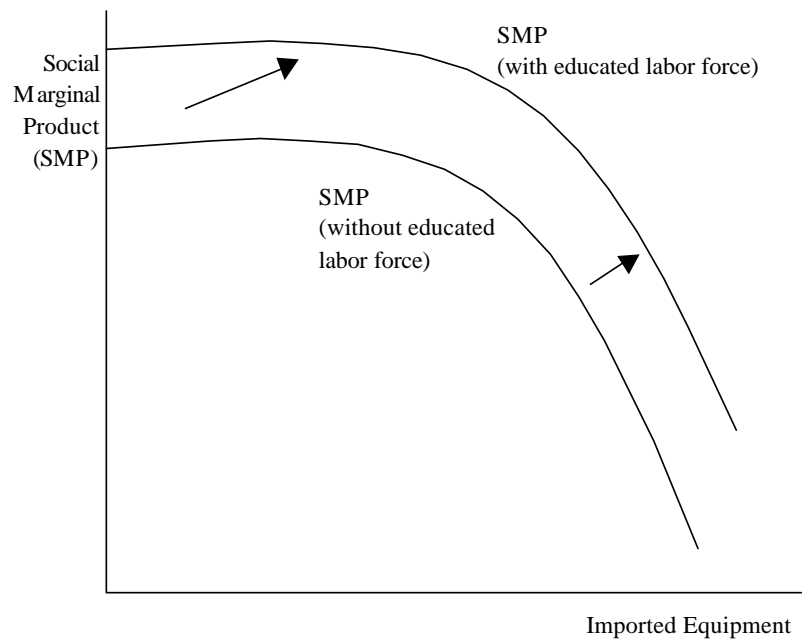

Figure 2 
Here again, there will be much that is scholarly on this subject the Conference, but I may cite Little (page 23) using the pretext that a Lecture justifies the informality of argumentation that a Conference paper does not:

It was largely from the experience of conducting this [1975, South Korean] survey, involving visits to the [ 28 randomly selected] firms ranging from 1.5 to 3.5 hours, that my own impressions of such matters as the acquisition of technology and skills on the part of the labour force... were formed. I also visited a number of high exporting mediumsize labour-intensive firms in Taiwan in $1976 \ldots$. Two points are mainly relevant in the present context. First, the technology was simple, non-proprietary and easily acquired.... Secondly, both Korean and Taiwan workers were very quick to learn. Employees would usually reach the expected productivity within a few weeks. This would probably not have been the case if the standards of primary education had not been high.

Of course, as these economies grew rapidly, the demand for secondary and higher education in turn would rise and a virtuous circle would follow: primary education would enhance the growth that the EP strategy brought whereas the enhanced growth would demand and lead to a more educated workforce. I see therefore primary education and literacy as playing an enhancing, rather than initiating, role in the EP-strategy-led East Asian drama, again contrary to what I think Dani Rodrik has suggested in yet another analysis of the role of education in development.

Thus, my story combines in its way three major elements, in that order: (i) the enhanced inducement to invest due to the EP strategy; (ii) the benefit from the surplus of domestic SMP over international cost of imported newer-vintage capital equipment; and (iii) the raising of this SMP by the presence of a literate workforce. But if the main plot is this, the story has doubtless many sub-plots. I will end on just one of them, especially as the analysis dates back to the early 1970s and to the NBER project, underlining the richness of the argumentation at the time that is hard to find in the somewhat caricatured accounts provided in the revisionist critiques. 


\section{Direct Foreign Investment (DFI)}

In my synthesis volume ${ }^{27}$ for the NBER Project findings, I had noted that among the advantages of the EP strategy, which the Project had found beneficial, one had to count the fact that trade barriersjumping DFI in the IS countries was likely to be limited for these countries by the size of the domestic market by which it was motivated - there are shades here of the inducement-to-invest argument I have made today, but only in the faintest strokes. Secondly, such DFI as was attracted in the IS countries was also likely to be less productive because it would be going into economic regimes characterized by significant trade distortions that could even generate negative value added at socially-relevant world prices - a possibility that was discussed by me (based on extension to the DFI issue of the contribution by Harry Johnson to the theory of immiserizing growth in tariff-distorted economies $)^{28}$ and then nailed down in well known articles into a certainty under certain conditions by Hirofumi Uzawa and by Richard Brecher and Carlos Diaz Alejandro independently.

I did say earlier that we all cite the many-country regressions when they go our way. So, let me mention that both these (thoroughly plausible in terms of their economic rationale) hypotheses have been examined, with some success, in cross-country regressions by another former student of mine, V.N. Balasubramanyam and his co-authors. ${ }^{29}$ So, this element of explanation may also be added to the explanation of East Asia's superior performance relative to that of the IS-strategy-plagued countries. ${ }^{30}$

27 Bhagwati, 1978, op. cit.

28 See Jagdish Bhagwati, "The Theory of Immiserizing Growth: Further Applications," in Michael Connolly and Alexander Swoboda (eds), International Trade and Money, Toronto University Press, Toronto, 1973.

${ }^{29}$ See, in particular, V.N. Balasubramanyam and M.A. Salisu, "EP, IS and Direct Foreign Investment in LDCs," in A. Koekkoek and L.B.M. Mennes (eds), International Trade and Global Development: Essays in Honour of Jagdish Bhagwati, Routledge: London, 1991, for the former hypothesis; and V.N. Balasubramanyam, M.A. Salisu, and David Sapsford, "Foreign Direct Investment and Growth in EP and IS countries," Economic Journal, January 1996, for an indirect test of the latter hypothesis (explaining growth as the dependent variable).

30 Of course, as Magnus Blomstrom has reminded me, I should also note that there is considerable evidence at the micro level of beneficial spillover effects from DFI, including from several studies he has undertaken in developing 


\section{The Westward Diffusion}

So, I conclude by noting that the East Asian alchemy seems to have been traveling westwards, lifting the economic performance of the NECs such as Indonesia and Thailand, and India now seems finally poised, with its economic reforms in the direction of global integration, to profit from it almost a quarter of a century late.

The miracle of East Asia can thus be explained; and having explained it, we can reproduce it. In that sense, it is more magic than miracle. But I will settle for magic, which is no less a spectacle than a miracle, and more consonant with our rational age.

countries. Reconciling this evidence with the contention that there is little evidence of TFP in the Lau-Young type studies remains an unresolved issue, however. 